\title{
Does screening of COPD deter smokers with normal lung function to quit smoking?
}

\author{
*Daniel Kotza, \\ Onno CP van Schayck ${ }^{a}$ \\ a Department of General Practice, \\ CAPHRI School for Public Health and \\ Primary Care, Maastricht University \\ Medical Centre, Maastricht, The \\ Netherlands.
}

\section{*Correspondence:}

Dr Daniel Kotz,

Department of General Practice, CAPHRI School for Public Health and Care, Maastricht University Medical Centre, P.O. Box 616, 6200 MD Maastricht, Maastricht, The Netherlands.

Tel: +314338 82893

Fax: +31433619344

E-mail: d.kotz@hag.unimaas.nl

Web: www.daniel-kotz.de

14th October 2010

C 2010 Primary Care Respiratory Society UK. All rights reserved

\section{Conflict of interest declaration}

OvS is advisor to the Dutch Asthma Foundation on a subject related to this publication. Moreover he is involved in a related scientific project funded by Pfizer. DK has nothing to declare.

\section{Dear Sir,}

The ongoing debate about the usefulness of COPD screening programs mainly focuses on the effect of such programs on patients' smoking behaviour. In their recent editorial', Quanjer and Enright state that smokers who are screened with normal lung function "may subconsciously use that information as an excuse to continue smoking". This belief is often used as an argument against COPD screening programs. But what is the evidence for this belief?

Several studies have been performed on the effect of COPD screening programs on smoking. Such studies, however, have usually been designed to assess whether confronting smoking patients with their lung function measurement increases smoking cessation rates - an important justification for COPD screening programs. Their results have been contradictory; of the two most recent randomised controlled trials, one showed an effect of telling smokers their lung age, ${ }^{2}$ whereas the other did not find an effect of confronting smokers with their airflow limitation. ${ }^{3}$

The latter study on a COPD screening program provided some additional evidence on the effect of normal spirometry on smoking cessation. Smokers screened with abnormal lung function entered the smoking cessation trial ${ }^{3}$ whereas the remaining smokers with normal lung function were followed up for more than two years and reassessed. ${ }^{4}$ The rate of smoking cessation in smokers screened with normal lung function $(9 \%)$ was not significantly different from the rate of quitting in the general population $(8-9 \%)$ or the rate of quitting in smokers screened with abnormal lung function who received " primary care as usual " for smoking cessation in the trial condition (10\%). ${ }^{4}$

The results from that study are in line with another recent study showing that spirometry and counselling had equal effects on smoking cessation both in smokers with normal and with abnormal lung function. ${ }^{5}$ Certainly, more research is needed on the effects of screening programs on healthy smokers. In the light of the present evidence, however, the concern that smokers screened with normal lung function may be deterred from stopping smoking seems to be less important in the discussion about the usefulness of COPD screening programs. With the help of screening programs, many smokers quit who would otherwise not do so. We should therefore be less inert with implementing such programs because for every continued year of smoking, middleaged smokers lose on average about three months of life expectancy. ${ }^{6}$

\section{References}

1. Quanjer PH, Enright P. Should we use 'lung age'? Prim Care Resp J 2010;19(3):197-9. http://dx.doi.org/10.4104/pcrj.2010.00045

2. Parkes $G$, Greenhalgh $T$, Griffin $M$, et al. Effect on smoking quit rate of telling patients their lung age: the Step2quit randomised controlled trial. BMJ 2008;336:598-600. http://dx.doi.org/10.1136 /bmj.39503.582396.25

3. Kotz D, Wesseling G, Huibers MJ, et al. Efficacy of confronting smokers with airflow limitation for smoking cessation. Eur Respir J 2009;33:754-62. http://dx.doi.org/10.1183/09031936.00116308

4. Kotz D, Wesseling G, Aveyard P, et al. Smoking cessation and development of respiratory health in smokers screened with normal spirometry. Respir Med 2010; In Press, Corrected Proof http://dx.doi.org/10.1016/j.rmed.2010.07.010

5. McClure JB, Ludman EJ, Grothaus L, et al. Impact of spirometry feedback and brief motivational counseling on long-term smoking outcomes: A comparison of smokers with and without lung impairment. Patient Education and Counseling 2010;80:280-3. http://dx.doi.org/10.1016/j.pec.2009.11.002

6. West R, Stapleton J. Clinical and public health significance of treatments to aid smoking cessation. Eur Respir Rev 2008;17:199-204. http://dx.doi.org/10.1183/09059180.00011005 